\title{
Making Public Policies for SSE Sustainable, Feminist-Conscious and Transformative: Exploring the Challenges
}

The feminist analysis of social and solidarity economy (SSE) practices in the six cases studied in the project (see box) identified a number of limitations that may undermine the existence, scope, effectiveness and sustainability of public policies for SSE. These related to (i) the ability of SSE initiatives to construct public actions (and exert pressure) for change; (ii) a disabling political environment and lack of political commitment; (iii) the nature of institutional support in place; (iv) the processes underlying SSE policy making and legislation; and (v) institutional, political and financial capacity of state institutions to act, and policy incoherence. The research findings point in particular to the problematic way in which states fulfil their responsibilities in the field of social reproduction as a structural limitation for the development of SSE initiatives. This constitutes a major impediment to the development of feminist and transformative public policies for SSE. Overcoming it will require action from governments, SSE organizations and civil society movements.

\section{The ability of SSE organizations to construct public actions for change}

The research found that SSE organizations are in constant struggle with the state. Most of the SSE initiatives studied (Argentina, Brazil, Kerala, Karnataka, Tamil Nadu) spend a considerable amount of their time and effort lobbying and pressuring governments to fulfil their obligation to protect the rights and livelihoods of their populations. This process is carried out through intermediaries, such as non-governmental organizations (NGOs) or trade unions (Tamil Nadu; Brazil; Kerala); through direct negotiations (Argentina; Karnataka); or through street protests and other forms of direct action (Argentina; Brazil; Tamil Nadu; Karnataka). Under certain conditions, SSE organizations may play an important role in challenging the state and in shaping the public policy agenda. SSE initiatives may succeed in some cases, and they may fail in others.

While the success or failure of SSE efforts depends on multiple factors beyond the scope of this Brief to discuss, the capacity of SSE organizations to act in the first place and the nature of demands brought forward to the state are rather the product of a politicization process within SSE organizations. This process is exemplified in the capacity of members of SSE organizations to construct collective political awareness regarding unmet needs, unfulfilled rights or injustices that affect them or the wider community. The feminist analysis undertaken in the research found that the capacity of women from marginalized communities to construct a common cause and a collective identity out of their individual subjective experiences of oppression may facilitate the formation of political subjectivities and shape the women's action-oriented activities. The role of feminist movements within this process was found to be crucial, particularly in directing the gaze towards gender injustices and formulating actions for change accordingly.
Box 1: Project Overview: Feminist Analysis of Social and Solidarity Economy Practices: Views from Latin America and India

Social and solidarity economy (SSE) has a potentially important role to play in reorienting economies and societies toward more equitable, inclusive and sustainable development. But it can only be truly transformative if it also addresses the reorganization of social reproduction, integrating the political goals of gender equality and more equitable power relations. Are SSE practices moving in the right direction?

Even though women play a major role in SSE activities, until very recently the interest of both academics and policy makers in SSE has lacked a gender perspective. Feminist research on unpaid care and domestic work is only beginning to inform policy making and implementation on the ground, and SSE activities that relate to social reproduction (that is, by which society reproduces itself) are often under-recognized. The different social relationships and gender hierarchies at work in SSE typically lack a feminist analysis.

This research project aimed to contribute empirical evidence and analytical insights to begin filling these gaps in SSE research and policies from a feminist perspective.

\section{India case studies}

- Karnataka: Udupi fisherwomen association

- Kerala: SEWA domestic workers association

- Tamil Nadu: Women's organizations against sand quarries in Kancheepuram District, Palar Valley

\section{Latin America case studies}

- Argentina: Community organizations providing care services in suburbs of Buenos Aires

- $\quad$ Bolivia: Producer associations in Batallas, Department of La Paz

- Brazil: Agroecological and feminist collective production groups in Vale do Ribeira, State of São Paolo

The project was funded by the Swiss Network for International Studies (SNIS). Find more information about the project here.

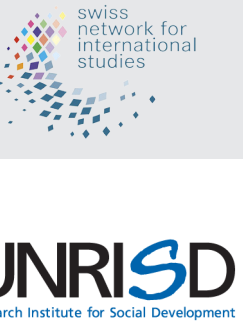


take on SSE can also be observed in India. While the term SSE or social economy (SE) is not used, federal and state governments' efforts to incorporate the unemployed into labour markets through associations, self-help groups and cooperatives reflect a similar rationale. In Brazil, solidarity economy policies have been the subject of semantic disputes: if for some, SSE represents an alternative model of work organization based on self-management, for others, policies in support of the sector are the equivalent of social assistance for those excluded from the labour market. In this context, the case study of agroecology and feminist collective production groups in Vale do Ribeira proposes a vision that goes beyond the linear logic of capitalist production and accumulation, and is based instead on an alternative understanding of the economy that encompasses the reproduction of all that is necessary for life. It takes the production and consumption of food as a starting point, and aims at democratization of all the power relations involved in this reproduction. The role of feminist organizations and rural women's movements in the coconstruction of public policies and their implementation is central to the development of this approach.

In some countries, SSE public policies and legal recognition are narrowly conceived, with SSE limited to social enterprises and support focusing primarily on financial sustainability and entrepreneurial management. Such characteristics do not necessarily apply to SSE initiatives that aim to transform social relations from a feminist perspective. This narrow conception also tends to be characterized by a "productive bias" that places reproductive activities in a secondary position to activities that centre on job creation. In Argentina for instance, the most important policies for the urban SSE sector focus mainly on microcredit and subsidies for the promotion of small businesses. Ellas Hacen, introduced in 2013 by the government of Argentina as a means to integrate women from marginalized communities into the labour market by facilitating the establishment of women's cooperatives and providing training, is one example. But this programme, and many others, tend to exclude communitybased care services. However, through public pressure and negotiation, some community-based care organizations managed to gain inclusion of some of their members in the programme and receive its support. This highlights how important it is for SSE entities to gain political awareness in order to claim rights and influence the public policy agenda.

The limited attention in public policies to social reproduction issues reflects the deeply rooted structural bias inherent in capitalist societies that views women's work as a service to the community rather than labour. Indeed, feminist analysis shows that public policies are often paternalistic and informed by a gendered worldview. As such, they reaffirm the hierarchies in the organization of productive and reproductive activities that characterize capitalist societies and sustain existing gender norms. In Brazil, for instance, the value of motherhood occupies a central place in the cash transfer programme Bolsa Familia. In Bolivia, rural women do not consider themselves workers, despite

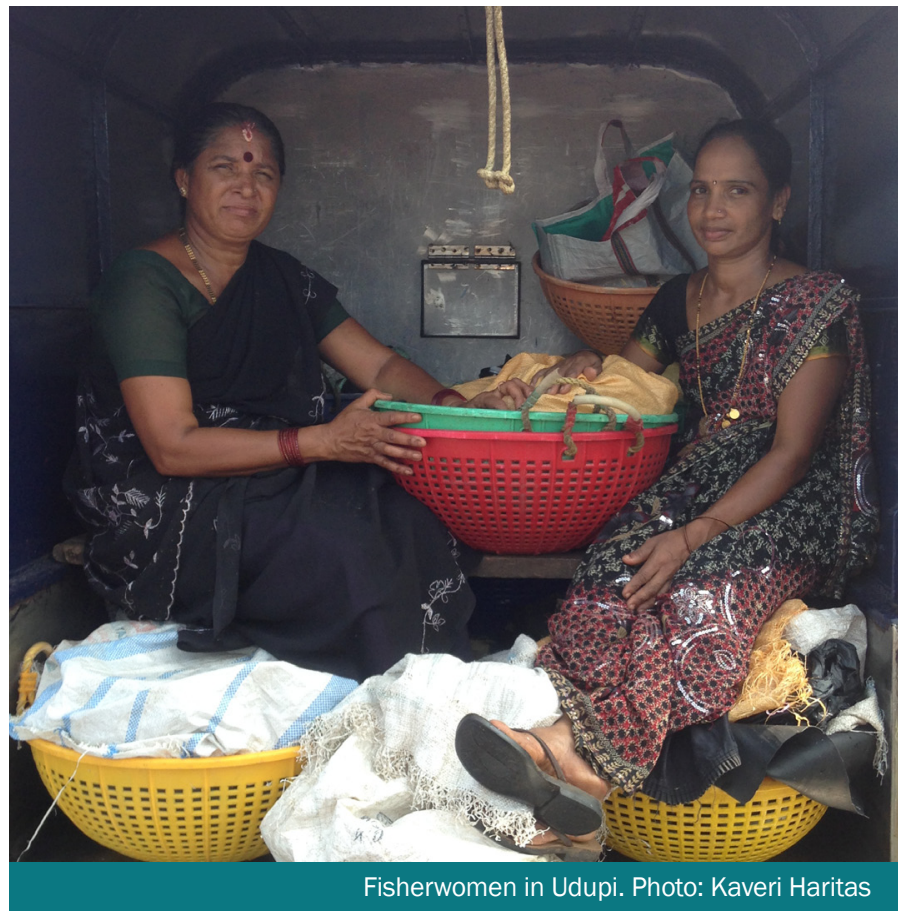

the many domestic, agricultural and petty trade tasks that they carry out, and, as a result, they do not claim rights to public services or advocate for policy change. Moreover, public policies aiming to integrate women into the labour market while fostering entrepreneurship offer training in traditionally "female" activities such as fashion and cooking, while ignoring agriculture. These programmes, while important, may trap women within predefined roles and expectations and may limit their emancipation. Similar processes were observed in Tamil Nadu, for example, where policies and projects promoting self-help groups tend to confine women beneficiaries to "domestic ghettos" like embroidery or small livestock rearing.

Such public policies foster a reality where women's work is valued less than men's labour. In Kerala, domestic work performed by women is seen as an extension of housework that a housewife performs in her own home. As such it is undervalued, poorly remunerated compared to domestic work performed by men, and poorly regulated. Gender bias in policies can also be found in relation to fishing communities in some Indian states, which provide cash and in-kind compensation during the monsoon season when fishing is banned. Family units headed by fishermen receive such compensation, whereas fisherwomen are not considered to be heads of household and may therefore be excluded from benefits.

\section{Processes underlying legislation and policy making}

Co-construction of public policies is an important process that opens up dialogue between SSE, its allies and governments, and allows for SSE voices to be heard and represented. It also allows SSE actors to assess the political and institutional capacity of state institutions to address 


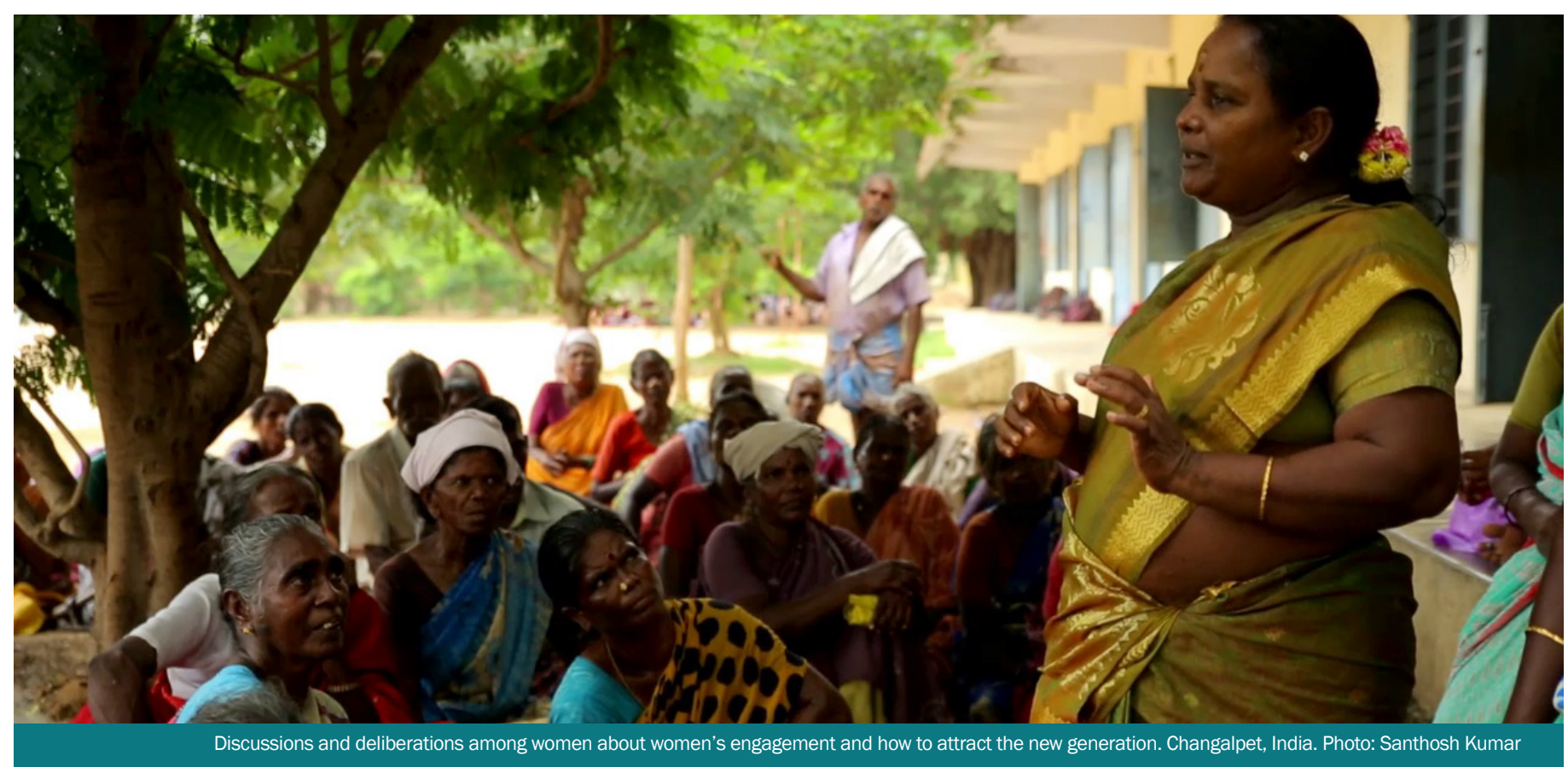

their needs effectively. Co-construction, ideally, allows for more effective SSE policy design, implementation and review. Top-down interventions, which exclude SSE actors and their allies in policy-making processes, no matter how well-intentioned they are, have downsides.

In Argentina for instance, decentralization and poor implementation of state programmes has increased the role of civil society organizations in the implementation of public policies (service provision in particular). While there are no formal processes of policy co-construction, public and political pressure applied by the community organizations of care workers studied in the research, with their allies in social and feminist movements, have influenced change in public policies. For example, when the government of the province of Buenos Aires first introduced the Programa Unidades de Desarrollo Infantil to support the development of childcare centres, no funding was allocated for the care workers themselves. Public mobilization and political pressure by community care workers and their allies eventually caused the provincial government to redirect some of the funds to the workers.

In Brazil there have been some moments of policy coconstruction, particularly when the Worker's Party was in power (2003-2016). During this period rural movements and NGOs benefited from unprecedented spaces of participation in the definition and management of agricultural development policies, such as public procurement of produce from family farms, rural credit, technical assistance schemes, and agroecology. A new Directorate of Rural Women Policies at the Ministry of Agrarian Development was established, staffed and funded. National and regional meetings were organized in which national agroecology, technical assistance and rural extension policies were defined. Within these spaces issues of gender equality were discussed and incorporated into the new policies. These policies further allowed executing entities, including NGOs, to develop their own proposals and programmes in the territories in which they operate. While these were important steps, the policies nevertheless remained experimental rather than universal ones, and were thus perceived as limited and bureaucratic in the eyes of some activists. Change in government since impeachment in May 2016 has severely impacted these policies. The Ministry of Agrarian Development disappeared and, although some policies and the main spaces of participation have been formally maintained, those who still participate in these processes say that their voices are not heard by the current government.

\section{The institutional and political capacity of state institutions, and policy coherence}

The capacity of state institutions to act-both in terms of translating policies and legislation into action plans and programmes, and the institutional capacity to implement them-is crucial for giving public policies meaning. In Bolivia for instance, despite the existence of a large number of laws in favor of strengthening producers' associations, concrete implementation of this normative framework lags behind. Policy implementation instead tends to favour social and political organizations (peasant unions) whose agendas do not include the economic or social demands of rural and urban producers' associations. In India, the state's acceptance of the Sustainable Development Goals and its constitutional commitment to equality and the right to life do not filter down into specific policies for fisherfolk, which recognize men as workers but not women. Thus the Udupi fisherwomen's association has to rely on local, contextual and transient agreements with lower levels of government to protect women's livelihoods, while the broader issue of equal recognition of their work is ignored. 
Where programmes do exist and are implemented, resources are not always adequate for addressing the evolving needs. In Argentina for instance, in 2009 the government introduced the Programa Ingreso Social con Trabajo: Argentina Trabaja to facilitate labour market integration through the creation of cooperatives. While the programme is meant for people in vulnerable situations and values collective work as an important tool to improve their lives, cooperative members are paid below minimum wage and have precarious social protection. The Programa Unidades de Desarrollo Infantil has similar shortcomings.

Policy incoherence further impedes the effectiveness of public policies for SSE. Indeed, the state is made up of diverse, and at times conflicting, entities, with the various ministries and departments at national and local levels having different priorities. In Argentina, Brazil and India, for instance, public policies for SSE coexist with neoliberal policies that prioritize corporations and capital accumulation. This duality may have negative consequences for SSE organizations and limit the impact of public policies for SSE. In Brazil for instance, the gov-ernment pursues a dual agricultural model. While family farming and agroecology have been reinforced through a range of policies, the development and advancement of this model has been limited by other policies intended to preserve the interests of big farmers and landowners. In Bolivia, the state's tendency to prioritize "strategic" sectors of the economy such as hydrocarbon extraction and mining at the expense of associative initiatives has weakened small-scale agriculture and livestock production. In India, the nexus between the state and the private sector threatens SSE initiatives. In Karnataka for example, state funds are directed towards capital-intensive enterprises

\section{Box 2: Project Team}

\section{Coordination}

Coordinator: Christine Verschuur; Co-coordinator: Filipe Calvão; Research assistants: Yira Lazala, Laïs Meneguello Bressan (Graduate Institute of International and Development Studies / IHEID)

\section{Country Research Teams}

Argentina: Marisa Fournier and Erika Loritz (Universidad Nacional de General Sarmiento / UNGS)

Bolivia: Ivonne Farah, Gabriela Ruesgas and Fernanda Sostres (CIDES, Universidad Mayor San André); Isabelle Hillenkamp (Institut de recherche pour le développement / IRD-CESSMA)

Brazil: Miriam Nobre (Sempreviva Organização Feminista / SOF); Isabelle Hillenkamp (Institut de recherche pour le développement / IRD-CESSMA)

India (Kerala): Rajib Nandi (Institute of Social Studies Trust) with inputs from Sheena Basheer and Sonia George India (Tamil Nadu): Isabelle Guérin (Institut de recherche pour le développement / IRD-CESSMA); Govindan Venkatasubramanian and Santosh Kumar (Institut Français de Pondichéry) India (Karnataka): Kaveri Haritas (O.P. Jindal Global University)

\section{Partners}

Kalpana Karunakaran (Indian Institute of Technology Madras); Jean-Louis Laville (Centre National des Arts et Métiers / CNAM); Ibrahim SaÏd (UNRISD) and business initiatives, such as the ownership of fishing boats, fish processing and ice factories, which generate fiscal revenues. These capital-intensive establishments are owned by men. Fisherwomen's work is considered livelihood and not business, and thus not beneficial to state revenues. Such perceptions and discursive framing obscure women's contributions: to ensuring the local distribution and sale of fresh fish, enabling access to cheap and nutritious food in the community, as well as the shadow work of cleaning fish that is sold in restaurants and exported by companies, thus contributing indirectly to state revenues through taxes and revenues generated by these enterprises.

\section{Recommendations}

- The research findings demonstrate how fragile and complex the SSE-state relationship is, in particular within a neoliberal capitalist market economy that prioritizes capital accumulation over solidarity practices and social reproduction. While the road towards a more equitable economic system and new social relations is still long, states in the meanwhile have the duty to fulfil their obligations in social reproduction. This should include support that enables SSE organizations to develop. Governments need to rethink their policies, and the governance of policy design and implementation, from a feminist perspective to ensure the sustainability and effectiveness of public policies for SSE.

- The role of SSE organizations, civil society organizations and progressive feminist movements are essential in this process, both in applying pressure on governments to maintain their support, namely in the field of social reproduction, and in working in collaboration with SSE organizations to explore the possibilities to reduce their dependence on the state. In this sense the engagement of feminist and other civil society movements with SSE, and a commitment of SSE organizations to feminism, should be promoted in the quest for feminist public policy. Enabling the articulation of networks of SSE initiatives in this endeavour is a strategy that may support the development of feminist and transformative SSE.

- Further research is needed to examine how dimensions of social reproduction can be better incorporated into public policies for SSE; and strategies to ensure that governments do not easily reverse progressive social and political reforms made by their predecessors, achieve greater autonomy and limit SSE dependence on the state and ensure its sustainability, and mitigate tensions and ensure that SSE public policies are effective and sustainable. 